\title{
Review Article \\ Decipher the Molecular Response of Plant Single Cell Types to Environmental Stresses
}

\author{
Mehrnoush Nourbakhsh-Rey and Marc Libault \\ Department of Microbiology and Plant Biology, University of Oklahoma, 770 Van Vleet Oval, Norman, OK 73019, USA \\ Correspondence should be addressed to Marc Libault; libaultm@ou.edu
}

Received 27 November 2015; Revised 18 February 2016; Accepted 28 February 2016

Academic Editor: Luis Fernando Revers

Copyright ( 2016 M. Nourbakhsh-Rey and M. Libault. This is an open access article distributed under the Creative Commons Attribution License, which permits unrestricted use, distribution, and reproduction in any medium, provided the original work is properly cited.

\begin{abstract}
The analysis of the molecular response of entire plants or organs to environmental stresses suffers from the cellular complexity of the samples used. Specifically, this cellular complexity masks cell-specific responses to environmental stresses and logically leads to the dilution of the molecular changes occurring in each cell type composing the tissue/organ/plant in response to the stress. Therefore, to generate a more accurate picture of these responses, scientists are focusing on plant single cell type approaches. Several cell types are now considered as models such as the pollen, the trichomes, the cotton fiber, various root cell types including the root hair cell, and the guard cell of stomata. Among them, several have been used to characterize plant response to abiotic and biotic stresses. In this review, we are describing the various -omic studies performed on these different plant single cell type models to better understand plant cell response to biotic and abiotic stresses.
\end{abstract}

\section{Use of Plant Single Cell Types to Study Plant Response to Environmental Stresses}

The multicellular complexity of the samples collected to characterize plant response to environmental stress is a major limitation to clearly depict the contribution of each cell type composing the sample in response to the stress. In other words, -omic studies at the level of plant organs reflect the average response of the different cell types composing the organ (Figure 1). In order to fully understand the exact contribution of each plant cell type in regulating plant response to environmental stresses, the transcriptome, epigenome, proteome, metabolome, and interactomes (e.g., protein-protein and protein-DNA interactions) of each plant cell type composing the sample and their changes in response to environmental stresses should be independently characterized [1]. For instance, the characterization of the transcriptional response of the soybean root hair cell to rhizobial inoculation allowed the identification of almost two thousand differentially expressed genes [2]. This single plant cell type analysis represents a significant improvement compared to previous studies describing few hundred genes differentially expressed in root sections in response to rhizobial inoculation $[3,4]$. Ultimately, the integration of these various datasets will lead to a global understanding of the molecular adaptation of plants to environment changes through the precise characterization of transcriptional regulatory networks [5]. Currently, the construction of these networks in response to environmental stresses is highly dependent on the nature of the samples used to collect biological information. For instance, working at the level of entire organs cannot depict the specific networks existing in each cell type composing the organ supporting the idea to study plant biological networks at the level of single cell types. Accordingly, this review highlights the recent progress in the field of plant adaptation in response to both biotic and abiotic stresses at the level of single cell types (Table 1).

\section{Isolation of Plant Single Cell Types}

The isolation of plant single cell types is limited by the cell wall, which provides both rigidity and structure to the plant and acts as a first barrier against pathogenic organisms. To 


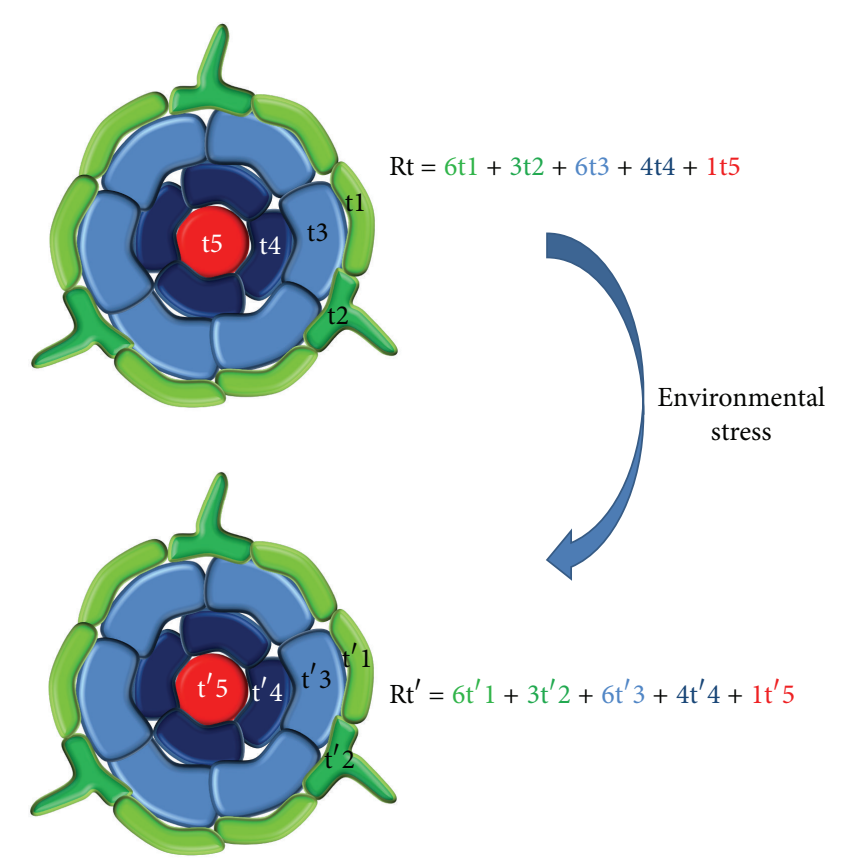

FIgURE 1: Root transcriptomic response to a stress ( $\mathrm{Rt}$ and $\left.\mathrm{Rt}^{\prime}\right)$ is the sum of the individual responses of each cell type composing the root ( $t 1$ to $t 5 ; t^{\prime} 1$ to $t^{\prime} 5$ ). Because plant cell transcriptomes are different between cell types, the cellular complexity of plant roots is not suitable to characterize gene networks. A single cell type model must be used to better characterize plant gene networks.

overcome this difficulty, different strategies were applied to isolate various cell types. These technologies include the use of cell sorting laser capture microdissection [6-9], sorting of single plant cell types upon cell type-specific GFP labeling and protoplastization $[10,11]$, and the application of the INTACT (Isolation of Nuclei TAgged in specific Cell Types) method which includes the labeling of single plant cell nuclei with a biotinylated nuclear envelope protein before their isolation using streptavidin-coated magnetic beads [12, 13]. Other methods have been applied to access in large quantities easily accessible single plant cell types such as cotton fiber and root hair cells [14-16]. More recently, an innovative methodology named Meselect which combined both a mechanical and an enzymatic treatment of the plant cells has been applied to isolate leaf epidermal, vascular, and mesophyll cells [17]. Lu et al. (2015) also developed another methodology allowing the isolation of generative cells (GCs), the sperm cells (SCs), and the vegetative nuclei (VN) from tomato pollens [18]. In this method GCs, SCs, and VN were isolated from germinated tomato pollen grains and growing pollen tubes and purified by Percoll density gradient centrifugation. Microscopic examination of fluorescein diacetate-stained samples confirmed the purity of GCs and SCs, respectively. Propidium iodide staining was used to confirm VN integrity.

Currently, only a limited number of single plant cell types have been isolated in quantities compatible with the application of -omic technologies. The most noticeable examples are the cotton fiber, pollen cells, and root hair cells [14, 16, 1922]. Various root cell types from the model plant Arabidopsis thaliana have also been isolated preliminary to their molecular analyses including response to environmental stresses [23-26]. Our understanding of the biology of the plant female gametophyte which is composed of antipodal, central, egg, and synergid cells is also beneficiating from single cell type analyses [27].

\section{Single Cell-Specific Transcriptomes in Response to Biotic and Abiotic Stress}

Compared to other -omic datasets, plant single cell type transcriptomes and their changes in response to environmental stresses are currently the most complete. For instance, multiple studies have characterized the transcriptomic profile of Arabidopsis thaliana root cells and their response to abiotic stresses including nutrient deprivation (i.e., iron and sulfur), salinity, and low $\mathrm{pH}$ values as well as in response to stresssignaling plant hormones such as abscisic acid [24, 25].

Among root cells and across plant species, the root hair cell is likely the best transcriptionally characterized single cell type based on the ease to isolate them from the rest of the root. The root hair transcriptome has been characterized across different plant species including $A$. thaliana $[13,26$, 28-31], Glycine max (i.e., 451 root hair specific transcripts characterized [2, 32]), and Medicago truncatula (i.e., 49 root hair specific transcripts characterized [33]). In legumes, this single plant cell type was also recently used as a model to study plant cell response to biotic stress because it is the first cell type infected by rhizobia, the nitrogen-fixing symbiotic bacteria [2, 33]. 219 and 79 soybean and Medicago genes were, repetitively, transcriptionally regulated in root hair cells in response to rhizobia including many genes functionally characterized for their role during nodulation [34]. Another plant single cell type model recently used to characterize the transcriptional changes occurring in response to pathogenic microorganisms was the $A$. thaliana mesophyll cell infected by the oomycete Hyaloperonospora arabidopsidis [35].

In addition to respond to various biotic stresses, plants are also constantly interacting, responding, and adapting to various abiotic stresses. Our understanding of those interactions is also benefiting from a single plant cell type transcriptomic approach. For instance, Sarah Assmann's group performed a transcriptomic analysis of $A$. thaliana guard cells in response to abscisic acid, a plant hormone acting on plant water conservation. 909 genes were specifically regulated in response to ABA in guard cells [36]. Plant resistance to heavy metal has also been investigated at the level of single plant cell types. For instance, trichomes are known to sequester heavy metals such as cadmium. Accordingly, a comparative transcriptomic analysis was conducted in Nicotiana tabacum trichomes in response to cadmium treatment [37]. Together, taking advantage of the specific biological function of single plant cell types, their transcriptomic analysis has the potential to reveal new plant regulatory genes in response to biotic and abiotic stresses due to the gain of sensitivity of the analysis. For instance, the barley $\beta$-extension EXPB7 gene which was 
TABLE 1: Various -omic analyses were conducted on different plant single cell types in response to both biotic and abiotic stresses.

\begin{tabular}{|c|c|c|c|}
\hline \multirow{2}{*}{ Cell type } & \multicolumn{3}{|c|}{ Omics } \\
\hline & Transcriptome & Proteome & Metabolome \\
\hline Trichome & $\begin{array}{l}\text { Nicotiana tabacum L. cv. Xanthi } \\
\quad \text { (pathogenic stress; [37]) }\end{array}$ & $\begin{array}{l}\text { Arabidopsis thaliana (cold, hormone } \\
\text { stimulus, and drought; [55]) } \\
\text { Artemisia annua L. (dehydration stress, } \\
\text { detoxification; [53]) } \\
\text { Nicotiana tabacum (oxidative stress; } \\
{[56,57] \text { ) }}\end{array}$ & \\
\hline Guard cell & $\begin{array}{l}\text { Arabidopsis thaliana (dehydration } \\
\text { stress; [36]) }\end{array}$ & $\begin{array}{c}\text { Brassica napus (ABA response; [59]) } \\
\text { Arabidopsis thaliana (ABA response; } \\
{[60] \text { ) }}\end{array}$ & $\begin{array}{l}\text { Vicia faba L. (darkness and } \\
\text { drought; [89]) } \\
\text { Arabidopsis thaliana (nitric } \\
\text { oxide response and ABA } \\
\text { response, pathogenal } \\
\text { infection, and UV } \\
\text { radiation; [90-94]) }\end{array}$ \\
\hline Mesophyll cell & $\begin{array}{l}\text { Arabidopsis thaliana (pathogenal } \\
\text { infection; [35]) }\end{array}$ & & \\
\hline Root hair & $\begin{array}{c}\text { Hordeum vulgare L. ssp. } \\
\text { spontaneum (drought stress; [38]) } \\
\text { Arabidopsis thaliana (heat, cold, salt } \\
\text { stress, oxidative stress, and abscisic } \\
\text { acid stimulus; [28-31]) } \\
\text { Glycine max (rhizobial infection; } \\
\text { [2]) } \\
\text { Medicago truncatula (rhizobial } \\
\text { infection; [33]) }\end{array}$ & Glycine max (rhizobial infection; [61-63]) & $\begin{array}{l}\text { Glycine max (rhizobial } \\
\text { infection; [96-98]) }\end{array}$ \\
\hline Pollen, pollen tube & $\begin{array}{l}\text { Arabidopsis thaliana (heat and } \\
\quad \text { osmotic stress; }[19,28])\end{array}$ & $\begin{array}{c}\text { Arabidopsis thaliana (pathogenic } \\
\text { infection, oxidative stress; [42, 44-47]) } \\
\text { Zea maize (oxidative stress; [48]) } \\
\text { Oryza sativa (pathogen infection, } \\
\text { oxidative stress; [43]) }\end{array}$ & \\
\hline Epidermal cell & $\begin{array}{c}\text { Mesembryanthemum crystallinum } \\
\text { (salinity stress; [88]) }\end{array}$ & & $\begin{array}{c}\text { Mesembryanthemum } \\
\text { crystallinum (salinity stress; } \\
{[85] \text { ) }}\end{array}$ \\
\hline Cotton fiber & $\begin{array}{l}\text { Gossypium arboreum L. (drought } \\
\text { stress; }[14,15] \text { ) }\end{array}$ & & \\
\hline
\end{tabular}

initially identified based on its differential expression in root hair cells in response to drought stress has been demonstrated to confer a better drought adaptation to the plant [38].

\section{Characterization of the Proteomic Response of Single Plant Cell Type to Environmental Stresses}

Proteins are the active molecules in the cells. The quantification of their relative abundance is critical to understand plant adaptation to environmental stresses. However, single cell type proteomes are challenging to establish because of the limited quantities of plant material available [39-41]. In addition, their posttranslational modifications are also affecting protein function and should logically be characterized at the level of single plant cell types.

A first effort in the establishment of single cell type proteome was the characterization of the pool of proteins in mature pollens. Pollen cell proteomics have been studied in different plant models such as Arabidopsis thaliana and Oryza sativa [42-45]. In Arabidopsis thaliana 130 differentially expressed proteins involved in pollen germination and pollen tube growth were identified via proteomic analyses [46]. Ultimately, proteomic analyses led to the establishment of the first protein reference map of mature pollen in Arabidopsis using two-dimensional gel electrophoresis (2DE), matrixassisted laser desorption/ionization time of flight (MALDITOF), and electrospray quadrupole time of flight-mass spectrometry (EQ-TOF-MS) [47]. In maize, a comparative proteomic analysis allowed the characterization of differentially expressed proteins involved in pollen tube development and plant defense [48]. Among those proteins, several participate in pollen resistance to environmental stresses. For instance, proteomic analysis in Arabidopsis pollen helped to reveal the role of the ABI1 phosphatase $2 \mathrm{C}$ as a negative regulator of ABA signaling [49]. Similarly, in response to osmotic stress, glucose regulated (GRPs) and LEA-like $A$. thaliana proteins were strongly induced to protect the cells $[47,50,51]$. 
Trichome has also been subject to various proteomic analyses across different plant species such as Artemisia annua, Arabidopsis, and tobacco [52-54]. The establishment of the trichome proteome in Arabidopsis thaliana confirms the important role of this single cell type in sulfur metabolism and detoxification to enhance plant defense mechanisms [55]. Upon the identification in 1543 proteins in tobacco leaf trichomes [56], several enzymes also related to the detoxification including glutathione-S-transferase (GST), ascorbateglutathione cycle enzymes, superoxide dismutases (SOD), cytosolic $\mathrm{Cu} / \mathrm{Zn} \mathrm{SOD}$, and peroxidases were characterized in response to oxidative stress [56, 57]. The functional categorization of the Arabidopsis trichome proteome based on gene ontology (GO) terms also confirmed the role of trichomes in plant adaptation to abiotic (cold, temperature, drought, and heavy metal) and biotic stresses [54]. Similarly, in tobacco, proteins were also identified for their role in biotic stress responses such as chitinases and glucanases [56].

The guard cell proteome revealed the abundance of proteins involved in signaling, membrane transport, glycolysis, photosynthesis light reaction, and fatty acid biosynthesis [58]. Using isobaric tag for relative and absolute quantitation (iTRAQ) technology, several ABA-response proteins were identified in Brassica napus and Arabidopsis guard cells [59, 60]. In B. napus, 66 ABA-dependent and 38 ABA-decreased proteins were reported to have a special function in calcium oscillation, ROS reaction, photosynthesis, and signaling [59].

Comparative proteomic analyses in soybean also led to the identification of several root hair specific proteins differentially accumulated in response to Bradyrhizobium japonicum inoculation including more than 100 heat shock proteins involved in protein folding and stress responses [61, 62 ]. To provide a more complete view about the changes in the proteome of soybean root hair cells in response to rhizobium, Nguyen et al. (2012) also established its phosphoproteome and identified 273 root hair specific phosphopeptides regulated in response to B. japonicum infection [63].

\section{Metabolomic Response of Single Plant Cell Types to Environmental Stresses}

Similar to the other -omic approaches, the analysis of the cell type-specific metabolomes is affected by multicellular complexity of the tissues selected. In addition to their diversity, metabolomic analyses also suffer from the low concentration of many metabolites supporting the need for single plant cell type metabolomic approaches.

Microcapillary method is applied for sampling plant single cells content by using the oil-filled glass microcapillaries mounted on the micromanipulator [64-67]. This method benefits from cellular turgor pressure to study plant organ water relations at the single cell level, which allows investigating cellular macromolecules $[68,69]$. The combination of the microcapillary method with other physical or chemical analytical methods (e.g., gas chromatography-time of flight-mass spectrometry (GC-TOF-MS) [70], laser capture microdissection (LCM), laser microdissection optionally coupled to laser pressure catapulting (LMPC) [71], and RT-PCR [67, 69]) helps researchers to characterize the metabolome of fully differentiated plant cell types [72]. Combined with the recent improvement of analytical technologies, the quantitative and qualitative analysis of plant single cell type metabolomes would provide new insights into the environmental stress responses of plant cells.

Various technologies are commonly used for metabolomic profiling including infrared spectroscopy [73], nuclear magnetic resonance (NMR) [74-76], mass spectrometry (MS) and gas chromatography-MS (GC-MS) [77, 78], matrixassisted laser desorption/ionization (MALDI) [79], capillary electrophoresis coupled with laser induced fluorescence detection (CE/LIF) [80] or mass spectrometry (CE/MS) [81, 82], CE-negative electrospray ionization-MS, and electrospray ionization (ESI) [83]. These techniques vary in speed, selectivity, and sensitivity.

Several metabolomic studies at the level of single plant cell types have been described. For instance, focusing on the epidermal bladder cell (EBC), a specialized trichome cell from Mesembryanthemum crystallinum known to be morphologically altered under salt stress [84], Barkla and VeraEstrella (2015) characterized their metabolomic response to salinity [85]. Comparing M. crystallinum EBC metabolomic salt-response with the metabolomes of other salt-tolerant plant species [86,87], specific classes of metabolites enhancing plant adaptation to high salinity such as sugars and sugar alcohols have been identified. Similarly, having the goal to enhance plant resistance in response to salinity and heavy metals, metabolomic analyses revealed the accumulation of sulfur and glutathione in Arabidopsis and tobacco trichomes [88].

In the Arabidopsis thaliana and Vicia faba guard cells, several metabolomic studies revealed the relationships existing between the accumulation of flavonoids, reactive oxygen species, abscisic acid, nitric oxide, and auxin as important components of the signaling cascade controlling the stomatal movements in response to osmotic stresses and pathogenic organisms such as Pseudomonas syringae [89-94]. For instance, the increase in phenolic and flavonoid compounds in the A. thaliana guard cells provides an additional protection against pathogens, insects, and UV-B radiation [90]. Lipidomic analysis of Commelina communis and $A$. thaliana guard cells also revealed the role of fatty acids in the stomatal response of plants to both abiotic and biotic stresses $[93,95]$.

Plant single cell type metabolomic response to biotic stresses has also been established such as the soybean root hair metabolome and its regulation in response to $B$. japonicum inoculation. A total of 2610 root hair metabolites were identified using two biochemical methodologies: gas chromatography-mass spectrometry (GC-MS) and ultraperformance liquid chromatography-quadrupole time of flightmass spectrometry (UPLC-QTOF-MS) [96]. Among them, 166 were highly regulated in response to $B$. japonicum inoculation including various flavonoids, amino acids, fatty acids, carboxylic acids compounds, and trehalose. The latter has been well described for its essential role during the nodulation process and, more specifically, its role on survival of the soybean symbiotic bacteria $[97,98]$. 
New approaches are currently developed allowing the noninvasive analysis of single plant cell metabolome associated with a robust quantification and detection of plant single cell metabolites. Infrared-laser ablation electrospray ionization (LAESI) and UV-laser desorption/ionization (LDI) are two methods minimizing sample preparation and manipulation. The latter does not require an external matrix providing a larger spatial resolution of the single cell [99]. Complementary to LDI technology, LAESI highlights the colocalization of metabolites and metabolomic networks in plant samples such as Spathiphyllum lynise and Aphelandra squarrosa [100]. The LAESI was also successfully applied to analyze the metabolome of single epithelial cells in Allium cepa, the Citrus aurantium oil glands, and Narcissus pseudonarcissus bulbs $[101,102]$. As a conclusion, LAESI and LDI are new noninvasive analytical methods compatible with the analysis of single plant cell metabolome. They represent attractive solutions to image known and unknown metabolomic networks in response to environmental stresses at the level of single plant cells.

\section{Conclusion}

Recent technological advances are now enabling the characterization of plant molecular responses to both biotic and abiotic stresses at the level of single plant cell types. Omic studies on entire plant organs mask the cell-specific characteristics and lead to a dilution of the molecular changes. Accordingly, the scientific community highlighted the need for single plant cell type approaches to provide a more precise molecular characterization of plants response to the abiotic and biotic stresses. The combination of different molecular approaches and their integration will reveal at a systems level the complexity of plant cell adaptation to the stresses.

For instance, using tomato pollen cell as a model, LopezCasado et al. (2012) generated a proteomic analysis using RNA-seq database [103]. Single cell system biology by combination of one or two -omic analyses can also provide a more dynamic model of the interactions between the plant and its environment [104]. Therefore, integrating single cell type-specific proteomes, transcriptomes, and metabolomes would provide a better understanding of plant model regulatory networks in response to environmental stresses [22].

\section{Competing Interests}

The authors declare that they have no competing interests.

\section{Acknowledgments}

This work was supported by the National Science Foundation (Plant Genome Research Program, no. IOS-1339194, and CAREER Program, no. IOS-1453613) and by the US Department of Agriculture-Department of Energy Feedstock Program (no. DE-SC0012629).

\section{References}

[1] T. Nelson, N. Gandotra, and S. L. Tausta, "Plant cell types: reporting and sampling with new technologies," Current Opinion in Plant Biology, vol. 11, no. 5, pp. 567-573, 2008.

[2] M. Libault, A. Farmer, L. Brechenmacher et al., "Complete transcriptome of the soybean root hair cell, a single-cell model, and its alteration in response to Bradyrhizobium japonicum infection," Plant Physiology, vol. 152, no. 2, pp. 541-552, 2010.

[3] D. P. Lohar, N. Sharopova, G. Endre et al., "Transcript analysis of early nodulation events in Medicago truncatula," Plant Physiology, vol. 140, no. 1, pp. 221-234, 2006.

[4] N. Høgslund, S. Radutoiu, L. Krusell et al., "Dissection of symbiosis and organ development by integrated transcriptome analysis of Lotus japonicus mutant and wild-type plants," PLoS ONE, vol. 4, no. 8, Article ID e6556, 2009.

[5] L. Pu and S. Brady, "Systems biology update: cell type-specific transcriptional regulatory networks," Plant Physiology, vol. 152, no. 2, pp. 411-419, 2010.

[6] V. P. Klink, N. Alkharouf, M. MacDonald, and B. Matthews, "Laser Capture Microdissection (LCM) and expression analyses of Glycine max (soybean) syncytium containing root regions formed by the plant pathogen Heterodera glycines (soybean cyst nematode)," Plant Molecular Biology, vol. 59, no. 6, pp. 965-979, 2005.

[7] N. Ithal, J. Recknor, D. Nettleton, T. Maier, T. J. Baum, and M. G. Mitchum, "Developmental transcript profiling of cyst nematode feeding cells in soybean roots," Molecular PlantMicrobe Interactions, vol. 20, no. 5, pp. 510-525, 2007.

[8] S. Santi and W. Schmidt, "Laser microdissection-assisted analysis of the functional fate of iron deficiency-induced root hairs in cucumber," Journal of Experimental Botany, vol. 59, no. 3, pp. 697-704, 2008.

[9] H. Takehisa, Y. Sato, M. Igarashi et al., "Genome-wide transcriptome dissection of the rice root system: implications for developmental and physiological functions," Plant Journal, vol. 69, no. 1, pp. 126-140, 2012.

[10] C. Zhang, F. C. Gong, G. M. Lambert, and D. W. Galbraith, "Cell type-specific characterization of nuclear DNA contents within complex tissues and organs," Plant Methods, vol. 1, no. 1, article 7, 2005.

[11] S. V. Petersson, A. I. Johansson, M. Kowalczyk et al., "An auxin gradient and maximum in the arabidopsis root apex shown by high-resolution cell-specific analysis of IAA distribution and synthesis," The Plant Cell, vol. 21, no. 6, pp. 1659-1668, 2009.

[12] R. B. Deal and S. Henikoff, “The INTACT method for cell typespecific gene expression and chromatin profiling in Arabidopsis thaliana," Nature Protocols, vol. 6, no. 1, pp. 56-68, 2011.

[13] R. B. Deal and S. Henikoff, "A simple method for gene expression and chromatin profiling of individual cell types within a tissue," Developmental Cell, vol. 18, no. 6, pp. 1030-1040, 2010.

[14] A. B. Arpat, M. Waugh, J. P. Sullivan et al., "Functional genomics of cell elongation in developing cotton fibers," Plant Molecular Biology, vol. 54, no. 6, pp. 911-929, 2004.

[15] K. V. Padmalatha, G. Dhandapani, M. Kanakachari et al., "Genome-wide transcriptomic analysis of cotton under drought stress reveal significant down-regulation of genes and pathways involved in fibre elongation and up-regulation of defense responsive genes," Plant Molecular Biology, vol. 78, no. 3, pp. 223-246, 2012. 
[16] M. Libault, L. Brechenmacher, J. Cheng, D. Xu, and G. Stacey, "Root hair systems biology," Trends in Plant Science, vol. 15, no. 11, pp. 641-650, 2010.

[17] J. Svozil, W. Gruissem, and K. Baerenfaller, "Proteasome targeting of proteins in Arabidopsis leaf mesophyll, epidermal and vascular tissues," Frontiers in Plant Science, vol. 6, article 376, 2015.

[18] Y. Lu, L. Wei, and T. Wang, "Methods to isolate a large amount of generative cells, sperm cells and vegetative nuclei from tomato pollen for "omics" analysis," Frontiers in Plant Science, vol. 6, article 391, 2015.

[19] J. D. Becker, L. C. Boavida, J. Carneiro, M. Haury, and J. A. Feijó, "Transcriptional profiling of arabidopsis tissues reveals the unique characteristics of the pollen transcriptome," Plant Physiology, vol. 133, no. 2, pp. 713-725, 2003.

[20] Q. Q. Wang, F. Liu, X. S. Chen, X. J. Ma, H. Q. Zeng, and Z. M. Yang, "Transcriptome profiling of early developing cotton fiber by deep-sequencing reveals significantly differential expression of genes in a fuzzless/lintless mutant," Genomics, vol. 96, no. 6, pp. 369-376, 2010.

[21] Z. Qiao and M. Libault, "Unleashing the potential of the root hair cell as a single plant cell type model in root systems biology," Frontiers in Plant Science, vol. 4, article 484, 2013.

[22] M. S. Hossain, T. Joshi, and G. Stacey, "System approaches to study root hairs as a single cell plant model: current status and future perspectives," Frontiers in Plant Science, vol. 6, article 363, 2015.

[23] K. Birnbaum, D. E. Shasha, J. Y. Wang et al., "A gene expression map of the arabidopsis root," Science, vol. 302, no. 5652, pp. 1956-1960, 2003.

[24] J. R. Dinneny, T. A. Long, J. Y. Wang et al., "Cell identity mediates the response of Arabidopsis roots to abiotic stress," Science, vol. 320, no. 5878, pp. 942-945, 2008.

[25] A. S. Iyer-Pascuzzi, T. Jackson, H. Cui et al., "Cell identity regulators link development and stress responses in the Arabidopsis root," Developmental Cell, vol. 21, no. 4, pp. 770-782, 2011.

[26] S. M. Brady, D. A. Orlando, J.-Y. Lee et al., "A high-resolution root spatiotemporal map reveals dominant expression patterns," Science, vol. 318, no. 5851, pp. 801-806, 2007.

[27] M. W. Schmid, A. Schmidt, and U. Grossniklaus, "The female gametophyte: an emerging model for cell type-specific systems biology in plant development," Frontiers in Plant Science, vol. 6, article 907, 2015.

[28] J. D. Becker, S. Takeda, F. Borges, L. Dolan, and J. A. Feijó, "Transcriptional profiling of Arabidopsis root hairs and pollen defines an apical cell growth signature," BMC Plant Biology, vol. 14, no. 1, article 197, 2014.

[29] P. Lan, W. Li, W.-D. Lin, S. Santi, and W. Schmidt, "Mapping gene activity of Arabidopsis root hairs," Genome Biology, vol. 14, no. 6, article R67, 2013.

[30] A. Bruex, R. M. Kainkaryam, Y. Wieckowski et al., "A gene regulatory network for root epidermis cell differentiation in Arabidopsis," PLoS Genetics, vol. 8, no. 1, Article ID e1002446, 2012.

[31] M. A. Jones, M. J. Raymond, and N. Smirnoff, "Analysis of the root-hair morphogenesis transcriptome reveals the molecular identity of six genes with roles in root-hair development in Arabidopsis," The Plant Journal, vol. 45, no. 1, pp. 83-100, 2006.

[32] M. Libault, A. Farmer, T. Joshi et al., "An integrated transcriptome atlas of the crop model Glycine max, and its use in comparative analyses in plants," The Plant Journal, vol. 63, no. 1, pp. 86-99, 2010.
[33] A. Breakspear, C. Liu, S. Roy et al., "The root hair 'infectome' of Medicago truncatula uncovers changes in cell cycle genes and reveals a requirement for Auxin signaling in rhizobial infection," The Plant Cell, vol. 26, no. 12, pp. 4680-4701, 2014.

[34] G. E. D. Oldroyd, "Speak, friend, and enter: signalling systems that promote beneficial symbiotic associations in plants," Nature Reviews Microbiology, vol. 11, no. 4, pp. 252-263, 2013.

[35] T. L. R. Coker, V. Cevik, J. L. Beynon, and M. L. Gifford, "Spatial dissection of the Arabidopsis thaliana transcriptional response to downy mildew using fluorescence activated cell sorting," Frontiers in Plant Science, vol. 6, article 527, 2015.

[36] R.-S. Wang, S. Pandey, S. Li et al., "Common and unique elements of the ABA-regulated transcriptome of Arabidopsis guard cells," BMC Genomics, vol. 12, article 216, 2011.

[37] E. Harada, J.-A. Kim, A. J. Meyer, R. Hell, S. Clemens, and Y.-E. Choi, "Expression profiling of tobacco leaf trichomes identifies genes for biotic and abiotic stresses," Plant and Cell Physiology, vol. 51, no. 10, pp. 1627-1637, 2010.

[38] X. He, J. Zeng, F. Cao et al., "HvEXPB7, a novel beta-expansin gene revealed by the root hair transcriptome of Tibetan wild barley, improves root hair growth under drought stress," Journal of Experimental Botany, vol. 66, no. 22, pp. 7405-7419, 2015.

[39] T. Okamoto, K. Higuchi, T. Shinkawa et al., "Identification of major proteins in maize egg cells," Plant and Cell Physiology, vol. 45, no. 10, pp. 1406-1412, 2004.

[40] M. Abiko, K. Furuta, Y. Yamauchi et al., "Identification of proteins enriched in rice egg or sperm cells by single-cell proteomics," PLoS ONE, vol. 8, no. 7, Article ID e69578, 2013.

[41] T. Uchiumi, T. Shinkawa, T. Isobe, and T. Okamoto, "Identification of the major protein components of rice egg cells," Journal of Plant Research, vol. 120, no. 4, pp. 575-579, 2007.

[42] I. S. Sheoran, K. A. Sproule, D. J. H. Olson, A. R. S. Ross, and V. K. Sawhney, "Proteome profile and functional classification of proteins in Arabidopsis thaliana (Landsberg erecta) mature pollen," Sexual Plant Reproduction, vol. 19, no. 4, pp. 185-196, 2006.

[43] S. Dai, L. Li, T. Chen, K. Chong, Y. Xue, and T. Wang, "Proteomic analyses of Oryza sativa mature pollen reveal novel proteins associated with pollen germination and tube growth," Proteomics, vol. 6, no. 8, pp. 2504-2529, 2006.

[44] J. Zou, L. Song, W. Zhang, Y. Wang, S. Ruan, and W.-H. Wu, "Comparative proteomic analysis of Arabidopsis mature pollen and germinated pollen," Journal of Integrative Plant Biology, vol. 51, no. 5, pp. 438-455, 2009.

[45] R. Holmes-Davis, C. K. Tanaka, W. H. Vensel, W. J. Hurkman, and S. McCormick, "Proteome mapping of mature pollen of Arabidopsis thaliana," Proteomics, vol. 5, no. 18, pp. 4864-4884, 2005.

[46] W. Ge, Y. Song, C. Zhang, Y. Zhang, A. L. Burlingame, and Y. Guo, "Proteomic analyses of apoplastic proteins from germinating Arabidopsis thaliana pollen," Biochimica et Biophysica Acta (BBA)_Proteins and Proteomics, vol. 1814, no. 12, pp. 1964-1973, 2011.

[47] S. Noir, A. Bräutigam, T. Colby, J. Schmidt, and R. Panstruga, "A reference map of the Arabidopsis thaliana mature pollen proteome," Biochemical and Biophysical Research Communications, vol. 337, no. 4, pp. 1257-1266, 2005.

[48] Y. Zhu, P. Zhao, X. Wu, W. Wang, M. Scali, and M. Cresti, "Proteomic identification of differentially expressed proteins in mature and germinated maize pollen," Acta Physiologiae Plantarum, vol. 33, no. 4, pp. 1467-1474, 2011. 
[49] W. Zhang, C. Qin, J. Zhao, and X. Wang, "Phospholipase $\mathrm{D} \alpha 1$-derived phosphatidic acid interacts with ABI1 phosphatase $2 \mathrm{C}$ and regulates abscisic acid signaling," Proceedings of the National Academy of Sciences of the United States of America, vol. 101, no. 25, pp. 9508-9513, 2004.

[50] W. Wang, B. Vinocur, and A. Altman, "Plant responses to drought, salinity and extreme temperatures: towards genetic engineering for stress tolerance," Planta, vol. 218, no. 1, pp. 1-14, 2003.

[51] Y.-O. Kim, J. S. Kim, and H. Kang, "Cold-inducible zinc fingercontaining glycine-rich RNA-binding protein contributes to the enhancement of freezing tolerance in Arabidopsis thaliana," The Plant Journal, vol. 42, no. 6, pp. 890-900, 2005.

[52] A. Sallets, M. Beyaert, M. Boutry, and A. Champagne, "Comparative proteomics of short and tall glandular trichomes of Nicotiana tabacum reveals differential metabolic activities," Journal of Proteome Research, vol. 13, no. 7, pp. 3386-3396, 2014.

[53] T. Wu, Y. Wang, and D. Guo, "Investigation of glandular trichome proteins in Artemisia annua L. using comparative proteomics," PLoS ONE, vol. 7, no. 8, Article ID e41822, 2012.

[54] S. Kryvych, S. Kleessen, B. Ebert, B. Kersten, and J. Fisahn, "Proteomics-the key to understanding systems biology of Arabidopsis trichomes," Phytochemistry, vol. 72, no. 10, pp. 1061-1070, 2011.

[55] S. Wienkoop, D. Zoeller, B. Ebert et al., "Cell-specific protein profiling in Arabidopsis thaliana trichomes: identification of trichome-located proteins involved in sulfur metabolism and detoxification," Phytochemistry, vol. 65, no. 11, pp. 1641-1649, 2004.

[56] E. Van Cutsem, G. Simonart, H. Degand, A.-M. Faber, P. Morsomme, and M. Boutry, "Gel-based and gel-free proteomic analysis of Nicotiana tabacum trichomes identifies proteins involved in secondary metabolism and in the (a)biotic stress response," Proteomics, vol. 11, no. 3, pp. 440-454, 2011.

[57] S. Amme, T. Rutten, M. Melzer et al., "A proteome approach defines protective functions of tobacco leaf trichomes," Proteomics, vol. 5, no. 10, pp. 2508-2518, 2005.

[58] S. Dai and S. Chen, "Single-cell-type proteomics: toward a holistic understanding of plant function," Molecular and Cellular Proteomics, vol. 11, no. 12, pp. 1622-1630, 2012.

[59] M. Zhu, B. Simons, N. Zhu, D. G. Oppenheimer, and S. Chen, "Analysis of abscisic acid responsive proteins in Brassica napus guard cells by multiplexed isobaric tagging," Journal of Proteomics, vol. 73, no. 4, pp. 790-805, 2010.

[60] Z. Zhao, B. A. Stanley, W. Zhang, and S. M. Assmann, "ABAregulated $G$ protein signaling in Arabidopsis guard cells: a proteomic perspective," Journal of Proteome Research, vol. 9, no. 4, pp. 1637-1647, 2010.

[61] J. Wan, M. Torres, A. Ganapathy et al., "Proteomic analysis of soybean root hairs after infection by Bradyrhizobium japonicum," Molecular Plant-Microbe Interactions, vol. 18, no. 5, pp. 458-467, 2005.

[62] L. Brechenmacher, T. H. N. Nguyen, K. Hixson et al., "Identification of soybean proteins from a single cell type: the root hair," Proteomics, vol. 12, no. 22, pp. 3365-3373, 2012.

[63] T. H. N. Nguyen, L. Brechenmacher, J. T. Aldrich et al., "Quantitative phosphoproteomic analysis of soybean root hairs inoculated with Bradyrhizobium japonicum," Molecular \& Cellular Proteomics, vol. 11, no. 11, pp. 1140-1155, 2012.

[64] A. Tomos, P. Hinde, P. Richardson, J. Pritchard, and W. Fricke, "Microsampling and measurements of solutes in single cells," in Plant Cell Biology: A Practical Approach, N. Harris and K. J. Oparka, Eds., pp. 297-314, Oxford University Press, Oxford, UK, 1994.

[65] A. Tomos, A. Korolev, J. Farrar, K. Nicolay, R. Bowtell, and W. Koeckenberger, "Water and solute relations of the carrot cambium studied at single-cell resolution," in Cell and Molecular Biology of Wood Formation, pp. 101-112, Bios, Oxford, UK, 2000.

[66] S. Brandt, J. Kehr, C. Walz, A. Imlau, L. Willmitzer, and J. Fisahn, "A rapid method for detection of plant gene transcripts from single epidermal, mesophyll and companion cells of intact leaves," The Plant Journal, vol. 20, no. 2, pp. 245-250, 1999.

[67] S. P. Brandt, "Microgenomics: gene expression analysis at the tissue-specific and single-cell levels," Journal of Experimental Botany, vol. 56, no. 412, pp. 495-505, 2005.

[68] A. D. Tomos and R. A. Leigh, "The pressure probe: a versatile tool in plant cell physiology," Annual Review of Plant Biology, vol. 50, no. 1, pp. 447-472, 1999.

[69] J. Kehr, "High resolution spatial analysis of plant systems," Current Opinion in Plant Biology, vol. 4, no. 3, pp. 197-201, 2001.

[70] M. Schad, R. Mungur, O. Fiehn, and J. Kehr, "Metabolic profiling of laser microdissected vascular bundles of Arabidopsis thaliana," Plant Methods, vol. 1, no. 1, article 2, 2005.

[71] J. Kehr, "Single cell technology," Current Opinion in Plant Biology, vol. 6, no. 6, pp. 617-621, 2003.

[72] A. D. Tomos and R. A. Sharrock, "Cell sampling and analysis (SiCSA): metabolites measured at single cell resolution," Journal of Experimental Botany, vol. 52, no. 356, pp. 623-630, 2001.

[73] S. G. Oliver, M. K. Winson, D. B. Kell, and F. Baganz, "Systematic functional analysis of the yeast genome," Trends in Biotechnology, vol. 16, no. 9, pp. 373-378, 1998.

[74] R. G. Ratcliffe and Y. Shachar-Hill, "Probing plant metabolism with NMR," Annual Review of Plant Biology, vol. 52, no. 1, pp. 499-526, 2001.

[75] J. K. M. Roberts, "NMR adventures in the metabolic labyrinth within plants," Trends in Plant Science, vol. 5, no. 1, pp. 30-34, 2000.

[76] R. Bligny and R. Douce, "NMR and plant metabolism," Current Opinion in Plant Biology, vol. 4, no. 3, pp. 191-196, 2001.

[77] O. Fiehn, J. Kopka, P. Dörmann, T. Altmann, R. N. Trethewey, and L. Willmitzer, "Metabolite profiling for plant functional genomics," Nature Biotechnology, vol. 18, no. 11, pp. 1157-1161, 2000.

[78] U. Roessner, A. Luedemann, D. Brust et al., "Metabolic profiling allows comprehensive phenotyping of genetically or environmentally modified plant systems," The Plant Cell, vol. 13, no. 1, pp. 11-29, 2001.

[79] D. Sturtevant, Y.-J. Lee, and K. D. Chapman, "Matrix assisted laser desorption/ionization-mass spectrometry imaging (MALDI-MSI) for direct visualization of plant metabolites in situ," Current Opinion in Biotechnology, vol. 37, pp. 53-60, 2016.

[80] K. Arlt, S. Brandt, and J. Kehr, "Amino acid analysis in five pooled single plant cell samples using capillary electrophoresis coupled to laser-induced fluorescence detection," Journal of Chromatography A, vol. 926, no. 2, pp. 319-325, 2001.

[81] S. Sato, T. Soga, T. Nishioka, and M. Tomita, "Simultaneous determination of the main metabolites in rice leaves using capillary electrophoresis mass spectrometry and capillary electrophoresis diode array detection," Plant Journal, vol. 40, no. 1, pp. 151-163, 2004.

[82] T. Soga, Y. Ueno, H. Naraoka, Y. Ohashi, M. Tomita, and T. Nishioka, "Simultaneous determination of anionic intermediates for 
Bacillus subtilis metabolic pathways by capillary electrophoresis electrospray ionization mass spectrometry," Analytical Chemistry, vol. 74, no. 10, pp. 2233-2239, 2002.

[83] R. D. Smith, J. A. Loo, C. G. Edmonds, C. J. Barinaga, and H. R. Udseth, "New developments in biochemical mass spectrometry: electrospray ionization," Analytical Chemistry, vol. 62 , no. 9, pp. 882-899, 1990.

[84] D.-H. Oh, B. J. Barkla, R. Vera-Estrella et al., "Cell type-specific responses to salinity-the epidermal bladder cell transcriptome of Mesembryanthemum crystallinum," New Phytologist, vol. 207, no. 3, pp. 627-644, 2015.

[85] B. J. Barkla and R. Vera-Estrella, "Single cell-type comparative metabolomics of epidermal bladder cells from the halophyte Mesembryanthemum crystallinum," Frontiers in Plant Science, vol. 6, article 435, 2015.

[86] R. Lugan, M.-F. Niogret, L. Leport et al., "Metabolome and water homeostasis analysis of Thellungiella salsuginea suggests that dehydration tolerance is a key response to osmotic stress in this halophyte," The Plant Journal, vol. 64, no. 2, pp. 215-229, 2010.

[87] D. H. Sanchez, F. L. Pieckenstain, F. Escaray et al., "Comparative ionomics and metabolomics in extremophile and glycophytic Lotus species under salt stress challenge the metabolic preadaptation hypothesis," Plant, Cell \& Environment, vol. 34, no. 4, pp. 605-617, 2011.

[88] G. Gutiérrez-Alcalá, C. Gotor, A. J. Meyer, M. Fricker, J. M. Vega, and L. C. Romero, "Glutathione biosynthesis in Arabidopsis trichome cells," Proceedings of the National Academy of Sciences of the United States of America, vol. 97, no. 20, pp. 11108-11113, 2000.

[89] X. Ou, Y. Gan, P. Chen, M. Qiu, K. Jiang, and G. Wang, "Stomata prioritize their responses to multiple biotic and abiotic signal inputs," PLoS ONE, vol. 9, no. 7, Article ID e101587, 2014.

[90] J.-M. He, X.-G. Ma, Y. Zhang et al., "Role and interrelationship of $\mathrm{G} \alpha$ protein, hydrogen peroxide, and nitric oxide in ultraviolet B-induced stomatal closure in Arabidopsis leaves," Plant Physiology, vol. 161, no. 3, pp. 1570-1583, 2013.

[91] T. Joudoi, Y. Shichiri, N. Kamizono et al., "Nitrated cyclic GMP modulates guard cell signaling in Arabidopsis," Plant Cell, vol. 25, no. 2, pp. 558-571, 2013.

[92] R. Desikan, M.-K. Cheung, J. Bright, D. Henson, J. T. Hancock, and S. J. Neill, "ABA, hydrogen peroxide and nitric oxide signalling in stomatal guard cells," Journal of Experimental Botany, vol. 55, no. 395, pp. 205-212, 2004.

[93] B. B. Misra, B. R. Acharya, D. Granot, S. M. Assmann, and S. Chen, "The guard cell metabolome: functions in stomatal movement and global food security," Frontiers in Plant Science, vol. 6, article 334, 2015.

[94] X. Jin, R.-S. Wang, M. Zhu et al., "Abscisic acid-responsive guard cell metabolomes of Arabidopsis wild-type and gpal G-protein mutants," The Plant Cell, vol. 25, no. 12, pp. 4789-4811, 2013.

[95] Q. Sun, J. Liu, Q. Zhang et al., "Characterization of three novel desaturases involved in the delta- 6 desaturation pathways for polyunsaturated fatty acid biosynthesis from Phytophthora infestans," Applied Microbiology and Biotechnology, vol. 97, no. 17, pp. 7689-7697, 2013.

[96] L. Brechenmacher, Z. Lei, M. Libault et al., "Soybean metabolites regulated in root hairs in response to the symbiotic bacterium Bradyrhizobium japonicum," Plant Physiology, vol. 153, no. 4, pp. 1808-1822, 2010.

[97] J. G. Streeter and M. L. Gomez, "Three enzymes for trehalose synthesis in Bradyrhizobium cultured bacteria and in bacteroids from soybean nodules," Applied and Environmental Microbiology, vol. 72, no. 6, pp. 4250-4255, 2006.

[98] J. G. Streeter, "Effect of trehalose on survival of Bradyrhizobium japonicum during desiccation," Journal of Applied Microbiology, vol. 95, no. 3, pp. 484-491, 2003.

[99] B. Bartels and A. Svatoš, "Spatially resolved in vivo plant metabolomics by laser ablation-based mass spectrometry imaging (MSI) techniques: LDI-MSI and LAESI," Frontiers in Plant Science, vol. 6, article 471, 2015.

[100] P. Nemes, A. A. Barton, and A. Vertes, "Three-dimensional imaging of metabolites in tissues under ambient conditions by laser ablation electrospray ionization mass spectrometry," Analytical Chemistry, vol. 81, no. 16, pp. 6668-6675, 2009.

[101] B. Shrestha and A. Vertes, "In situ metabolic profiling of single cells by laser ablation electrospray ionization mass spectrometry," Analytical Chemistry, vol. 81, no. 20, pp. 8265-8271, 2009.

[102] B. Shrestha, J. M. Patt, and A. Vertes, "In situ cell-by-cell imaging and analysis of small cell populations by mass spectrometry," Analytical Chemistry, vol. 83, no. 8, pp. 2947-2955, 2011.

[103] G. Lopez-Casado, P. A. Covey, P. A. Bedinger et al., "Enabling proteomic studies with RNA-Seq: the proteome of tomato pollen as a test case," Proteomics, vol. 12, no. 6, pp. 761-774, 2012.

[104] F. S. O. Fritzsch, C. Dusny, O. Frick, and A. Schmid, "Single-cell analysis in biotechnology, systems biology, and biocatalysis," Annual Review of Chemical and Biomolecular Engineering, vol. 3, pp. 129-155, 2012. 

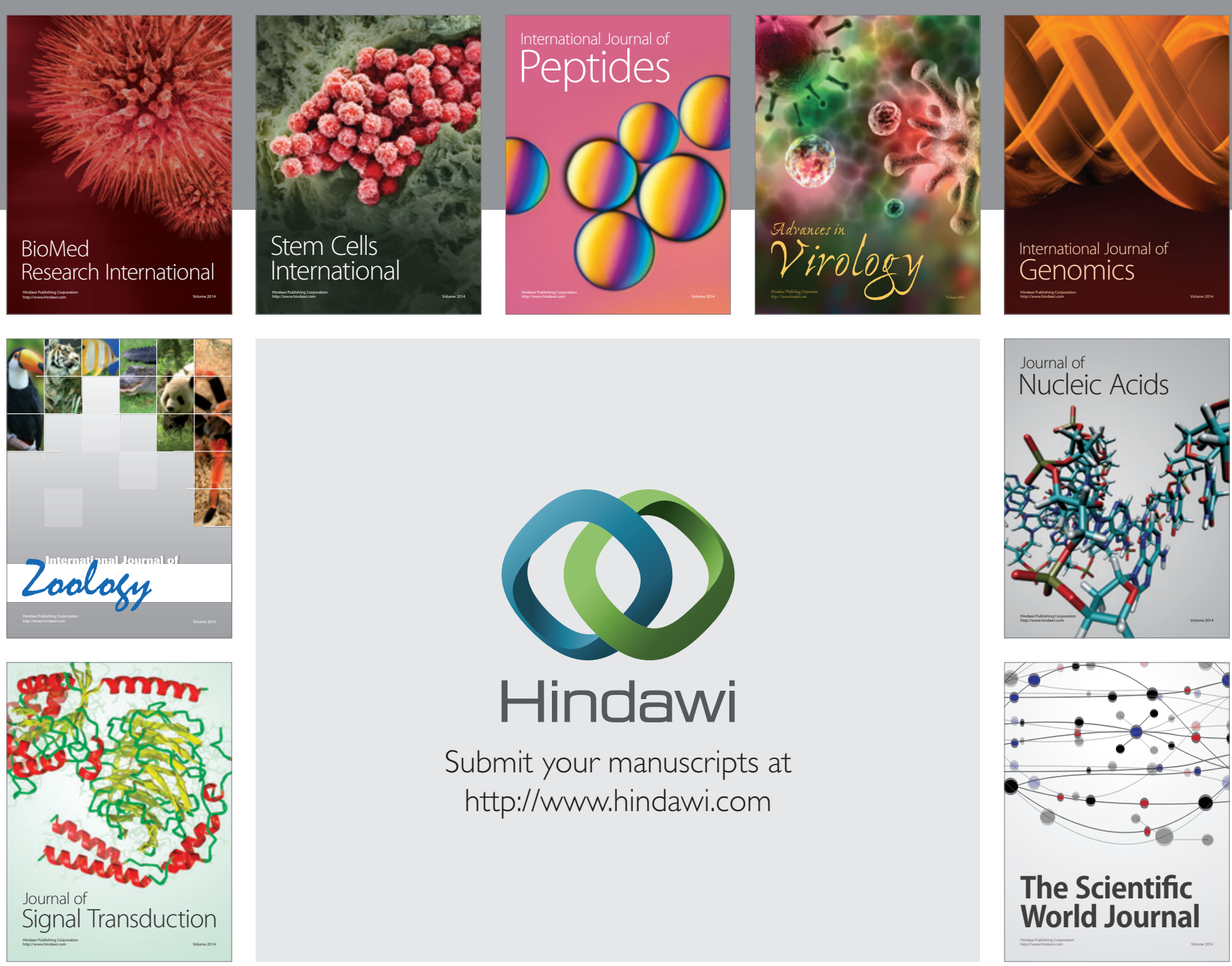

Submit your manuscripts at

http://www.hindawi.com
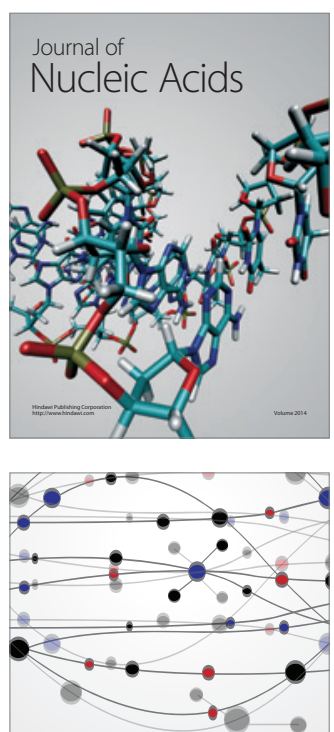

The Scientific World Journal
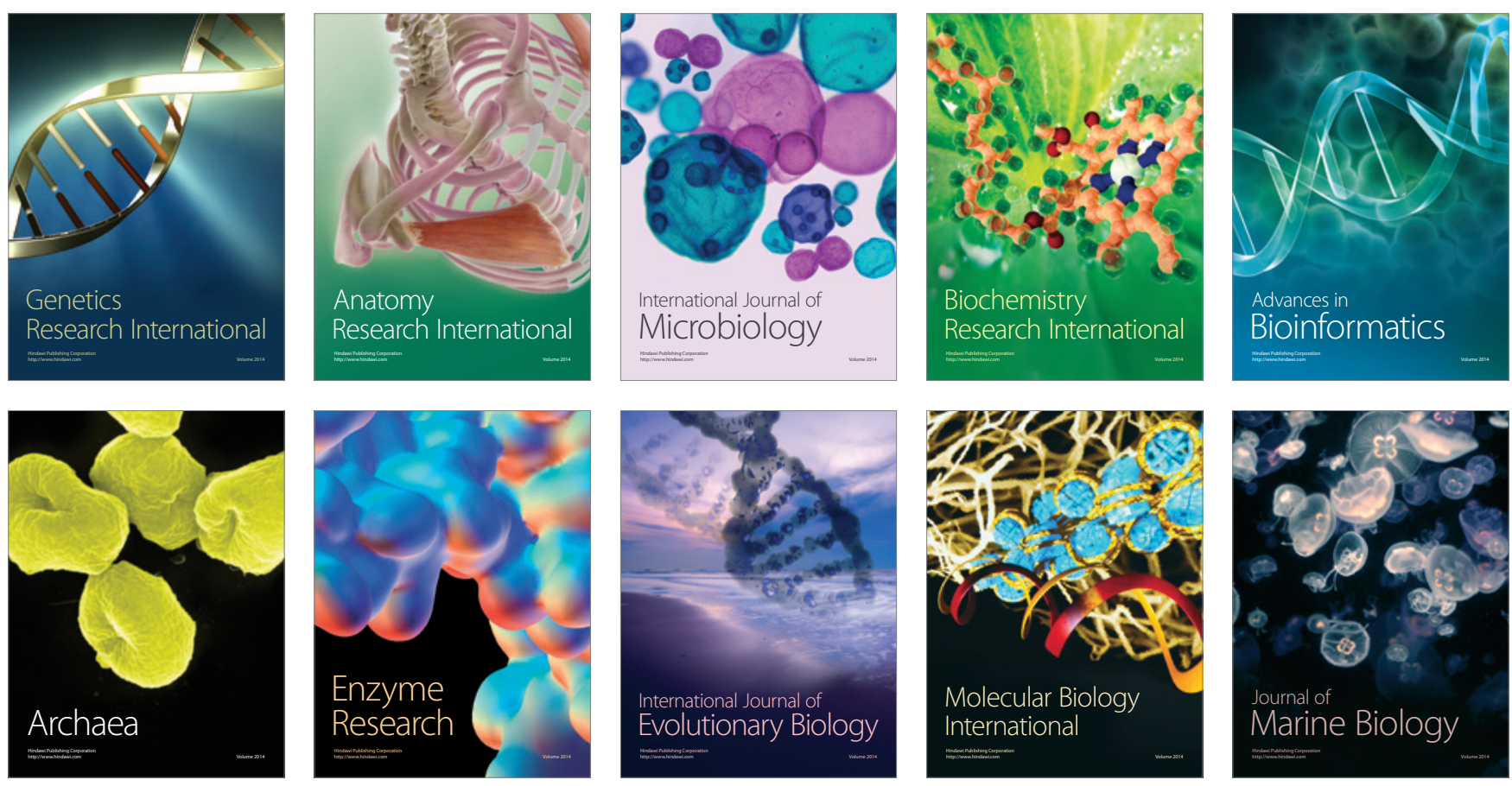